\title{
A Competition Analysis based on Patents of Chinese Electric Industry
}

\author{
Qingyuan $\mathrm{Wu}^{\text {a }}$, Sidi Zhao ${ }^{*}$, Lingnan $\mathrm{He}^{c}$ \\ ${ }^{a}$ Beijing Normal University, Zhuhai campus, China \\ ${ }^{\mathrm{b}}$ School of Management, Jilin University, China \\ ${ }^{\mathrm{c}}$ The School of Communication and Design, Sun Yat-sen University, China \\ *Corresponding author: Sidi Zhao, bachelor, rongruo6626@163.com
}

\begin{abstract}
This paper selected 20 electrical companies' patents as study subjects. From surface features level, we analysed patents information in growth rates of patent applications, the distribution of patent types and IPC types, and patents quality evaluation. From content features level, we studied the patents topic clustering via LDA and the network centrality via UCINET. Thus we excavated the internal information of patents data and the technology competitive situation of the Electric Industry, to learn the competitive focus, industry technology innovation, and production and management trends. Then we provide those electrical companies with reference data to formulate development strategies.
\end{abstract}

Key words: patent analysis; electric Industry; LDA; topic clustering; UCINET; hot technology

\section{Introduction}

In the past 30 years, China has achieved phenomenal economic growth, but has paid a heavy price for environmental pollution. The government regards energy saving and emission reduction as a key factor first, to accelerate the development of an environment-friendly and conservation-minded society. During the 12th Five-Year Plan period, the industrial structure of electrical industry promoted unceasingly optimizes, and energy management made considerable progress. To further extend strategic thinking of the 12th Five-Year Plan, electrical industry will contribute increasingly important efforts in ecological civilization construction during 13th Five Year Plan.

As an important form of competition situation, patents contain the current technology competitive information of electrical industry. To obtain competitive technical intelligence and the research and development trends of electrical industry, this paper analyses patents data of 20 electrical companies to learn the advantage of these companies in future competition.

\section{Related works}

The results of WIPO showed that using patent intelligence effectively can reduce the time it takes to develop new technology by $60 \%$ and save research and development costs by $40 \%$. WIPO also pointed that patent documents contain at least $90 \%$ global technology information. Begun in the 1990s, scholars appreciated the importance of patent subject analysis for competitive intelligence at home and abroad. Their researches are concentrated on mining structured information provided by patent database, and keywords co-occurrence analysis is the most common method of patent subject analysis ${ }^{1}$. 
Jintao Gong et al. ${ }^{2}$ (2013), used the State Intellectual Property Office of P. R. China as the data source, and excavated the technology R\&D (research and development) level, distribution of core technician and research collaboration status for wind power industry via Ucinet, a kind of social network analysis tool.

Huixin Zhong ${ }^{3}$ (2014), focused on the patent information of LED industry in Zhuhai, China. From the surface features level, he has been analysed the distribution of patent types, patents quality evaluation and the distribution of IPC types. From content features level, he studied the competitive situation of targeted industry through technology clustering and technology distribution of industry chain.

Hongyu Lee et al. ${ }^{4}$ (2015), first proposed a theory framework composed of four steps for enterprise positioning analysis based on patent information - in particular, measureing the degree of technology R\&D activity, identifying core technology, classifying technology domains and positioning technology. Their study supplements the theory about technology positioning in patent analysis.

Patent analysis is a unique and practical analysis method in enterprise competition strategy analysis, it also is frequently used in excavating enterprise competitive intelligence ${ }^{5}$. Patent analysis contains quantitative and qualitative analysis. Quantitative analysis can explain patent information by different indicators methods, to obtain the patent intelligence trend. The major research of qualitative analysis is the content features of patent documents, and we could determine the technology's maturity level with it. For example, a theory-based patent indicates the technology is not yet mature ${ }^{6}$, but an application-based patent means the technology is mature enough.

\section{Empirical analysis}

\subsection{Data collection}

We used the SooPAT as the source of our data, and download the patent documents information of 20 typical companies as our research object, such as Schneider, ABB, SFERE, PILOT, etc.

\subsection{Surface feature analysis}

\subsubsection{Essential analysis}

To some degree, total patent filings can represent the technical level, research and development ability of one enterprise. And the patent is divided into 3 types in China: invention, utility-model and design. Inventions with substantive review and a high degree of innovation cover wide scope, and it is far greater than utility-model and design in terms of valuable technologies. So this paper measures the quality of patents by invention percentage. You can refer to Eq. (1) to obtain the invention percentage, and refer to Table 1 to obtain the distribution of patent types.

Invention percentage $=$ inventions $/$ total patents

According to the invention percentage ranking, ABB and Schneider are the absolute leaders both in total filings and patent quality. It is noteworthy that the applications of Acrel, SFERE 
and PILOT declined significantly in 2012, whose patent quality are a little low. It shows the patents mainly composed of utility-models and designs are susceptible to economic fluctuation. And it's urgent for domestic enterprises to improve their patent quality.

Table 1 - The distribution of patent types

\begin{tabular}{|l|l|l|l|l|l|l|l|}
\hline \multirow{2}{*}{$\begin{array}{l}\text { business } \\
\text { name }\end{array}$} & \multicolumn{2}{l|}{ inventions } & \multicolumn{2}{l|}{ utility-models } & \multicolumn{2}{l|}{ designs } \\
\cline { 2 - 7 } quantity & percentage & quantity & percentage & quantity & percentage & \\
\hline Schneider & 1490 & $59.1 \%$ & 772 & $30.6 \%$ & 260 & $10.3 \%$ & 2522 \\
\hline ABB & 1252 & $70.53 \%$ & 350 & $19.72 \%$ & 173 & $9.75 \%$ & 1775 \\
\hline Acrel & 40 & $15.81 \%$ & 96 & $37.94 \%$ & 117 & $46.25 \%$ & 253 \\
\hline SFERE & 22 & $13.25 \%$ & 78 & $46.99 \%$ & 66 & $37.76 \%$ & 166 \\
\hline CET & 35 & $21.21 \%$ & 107 & $64.85 \%$ & 23 & $13.94 \%$ & 165 \\
\hline PILOT & 27 & $32.53 \%$ & 46 & $55.42 \%$ & 10 & $12.05 \%$ & 83 \\
\hline TIANSU & 26 & $34.67 \%$ & 33 & $44.00 \%$ & 16 & $21.33 \%$ & 75 \\
\hline JUNHAO & 13 & $20.97 \%$ & 47 & $75.81 \%$ & 2 & $3.22 \%$ & 62 \\
\hline ESDTEK & 15 & $25.42 \%$ & 29 & $49.15 \%$ & 15 & $25.42 \%$ & 59 \\
\hline Huasu & 4 & $13.33 \%$ & 23 & $76.67 \%$ & 3 & $10.00 \%$ & 30 \\
\hline Accuenergy & 2 & $8.7 \%$ & 7 & $30.4 \%$ & 14 & $60.9 \%$ & 23 \\
\hline Persagy & 14 & $82.4 \%$ & 1 & $5.9 \%$ & 2 & $11.7 \%$ & 17 \\
\hline Technovator & 8 & $47.06 \%$ & 6 & $35.29 \%$ & 3 & $17.65 \%$ & 17 \\
\hline SOGOMEI & 4 & $50.00 \%$ & 0 & 0 & 4 & $50.00 \%$ & 8 \\
\hline TFRC & 1 & $14.29 \%$ & 6 & $85.71 \%$ & 0 & 0 & 7 \\
\hline HZKL & 2 & $33.33 \%$ & 3 & $50.00 \%$ & 1 & $16.67 \%$ & 6 \\
\hline Narun & 0 & 0 & 4 & $100 \%$ & 0 & 0 & 4 \\
\hline ZXHA & 1 & $25.00 \%$ & 3 & $75.00 \%$ & 0 & 0 & 4 \\
\hline $\begin{array}{l}\text { AUTO- } \\
\text { UNION }\end{array}$ & 3 & $100 \%$ & 0 & 0 & 0 & 0 & 3 \\
\hline EF-ACS & 1 & $50.00 \%$ & 1 & $50.00 \%$ & 0 & 0 & 2 \\
\hline
\end{tabular}

\subsubsection{Changes in annual patent applications}

Owing to the absolute advantage of Schneider and ABB, we compare and analyse annual patent applications and annual growth rates from international and domestic this two parts, to make the chart more intuitive. Annual patent applications means new applications of every enterprise each year.

We can see that Schneider applied for a patent in 1994 in Fig. 1 below. Its annual applications increases year-by-year and reach its peak for 448 patents in 2012.ABB applied for a patent in 2011, and its annual applications has the same form. And in Fig. 2, there shows the applications' change of 18 domestic enterprises from 2002. It's easy to find that these companies' patent application fluctuate wildly with a maximum 38 patents, from which we can know technology development of domestic electrical industry is less stable.

There is a down trending of the application growth rate of ESDTEK for nearly four years, which reveals its insufficient strength for development. But these same domestic enterprises which enter the market early, Acrel and SFERE maintain a constant rate of growth and a stable technological level. It is not hard to find the applications of most companies declined significantly in 2012, which means electric industry is susceptible to economic fluctuation. Due to the early start and larger scale of Schneider and ABB, they far outpaced 


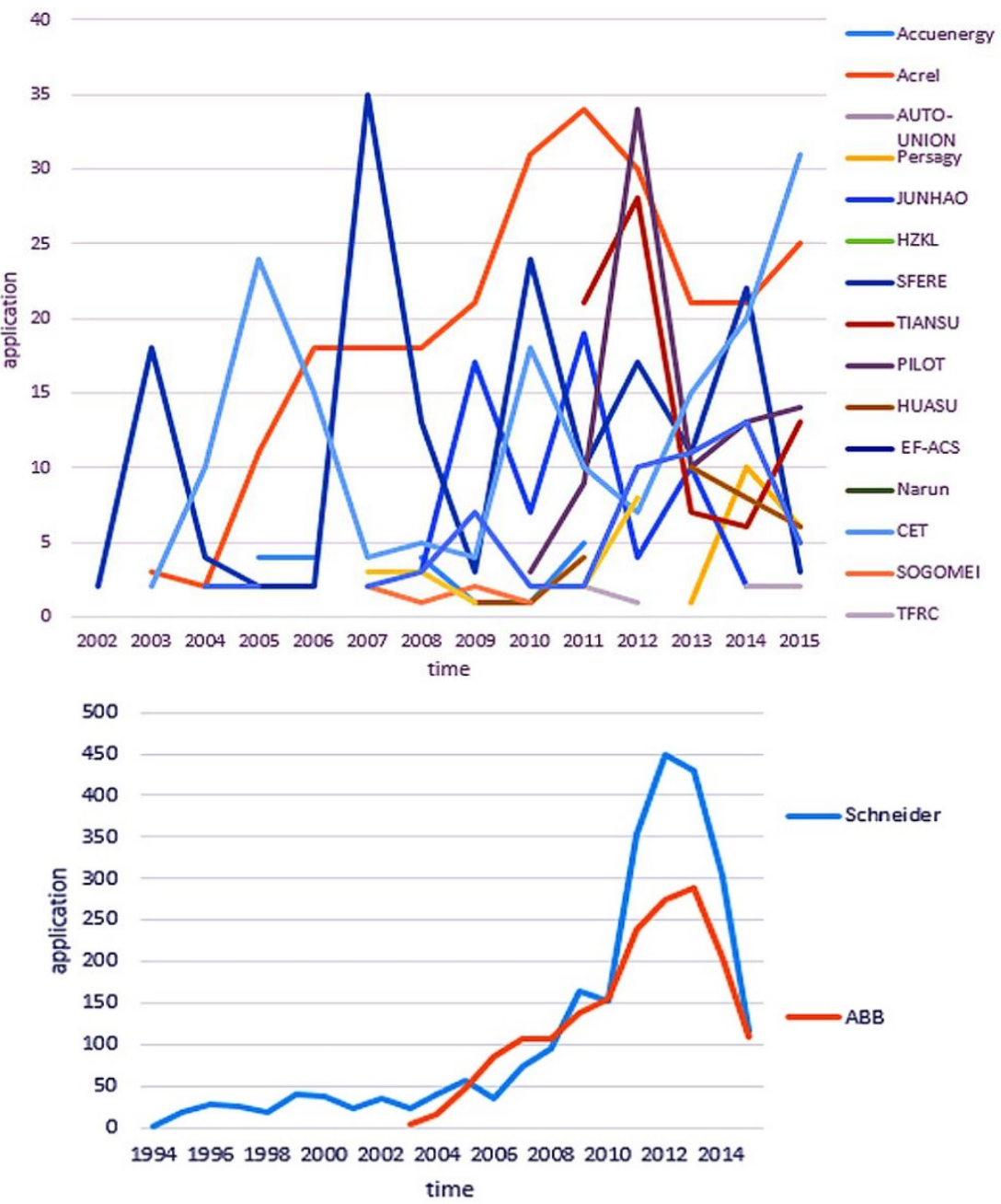

Fig. 1-Annual patent applications of domestic and international enterprise
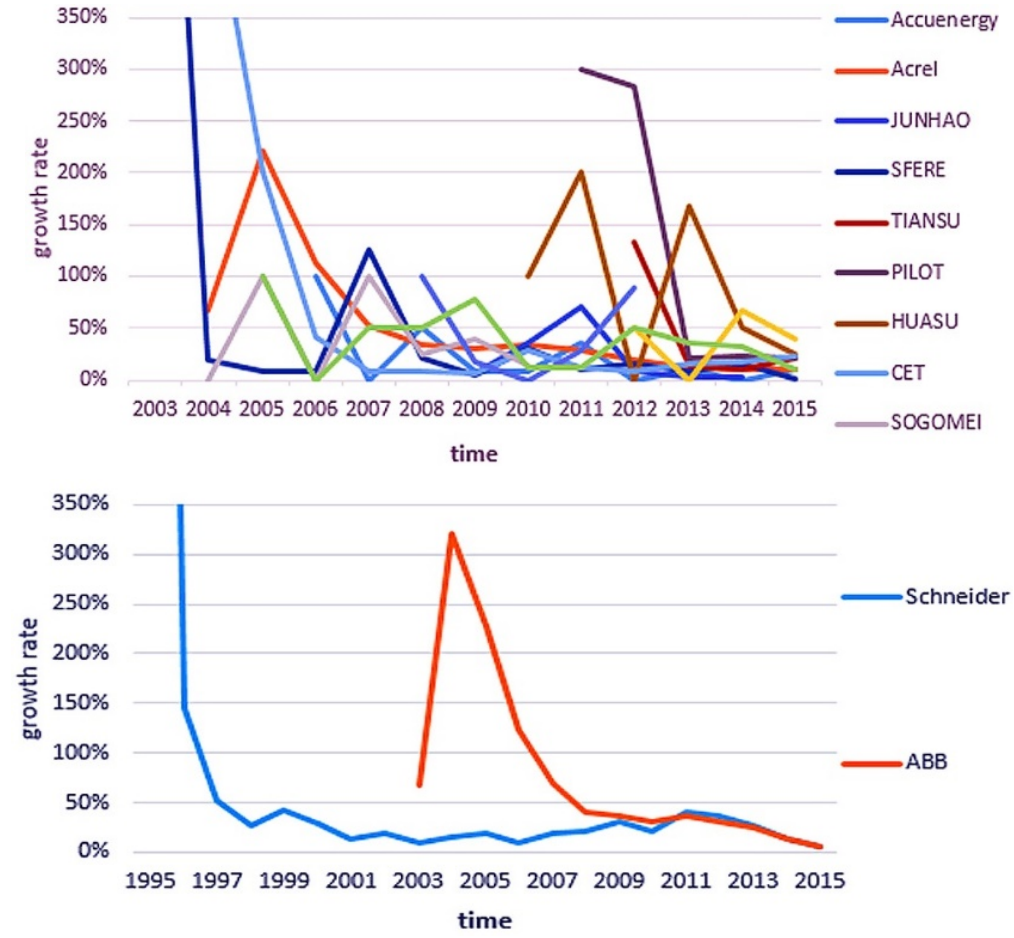

Fig.2-Annual patent applications growth rates of domestic and international enterprise 
domestic enterprises in research and development level. There is a very large room for development of electric enterprises in China.

\subsubsection{The distribution of IPC}

In order to reflect the distribution of technology domains clearly, the classification number of total 5281 patents has been classified and arranged in order. We choose the top 10 of the industry involved 133 IPC subclasses as the research object, which are showed in Table 2.

Table 2- IPC subclass of electric industry (top 10)

\begin{tabular}{|l|l|l|}
\hline IPC & Quantity & Instructions \\
\hline H01H & 1063 & electricity switch ; relay; selector; emergency retractor \\
\hline G01R & 371 & measuring electrical variables, measuring magnetic variable \\
\hline H02B & 361 & switchboard, substation or switching device \\
\hline H02J & 281 & circuit device or system; electric storage system \\
\hline H02H & 212 & emergency protection circuit device \\
\hline H01F & 203 & magnet; inductance; transformer; choice of magnetic material \\
\hline H02M & 197 & $\begin{array}{l}\text { The device is use in power supply system and the conversion between alternating } \\
\text { current (ac) and alternating current (ac), ac and direct current (dc), or dc and dc; the } \\
\text { conversion between input power to the output power of ac or dc } \\
\text { regulation of them }\end{array}$ \\
\hline G05B & 169 & monitoring or testing device of control system and regulating system \\
\hline G06F & 166 & processing of digital data \\
\hline H01R & 161 & semiconductor device; solid electronic devices don't belong to other category \\
\hline
\end{tabular}

The top 10 subclasses of 3184 patents are taking $60 \%$ of total applications. The patents of current electric industry are concentrated in H-section (Electricity) and G-section (Physics).

\subsection{Topic clustering analysis}

The paper analyses the topic cluster from domestic and abroad. The data oversea consists of the patents' summary of Schneider and ABB applied abroad, and domestic data consists of the patents' summary of 20 companies applied in China.

\subsubsection{Text pretreatment}

1. Remove the symbol

2. Word segmentation-dividing continuous character sequences into basic units (word or word group).

3. Statistic the word frequency

4. Combination of synonyms

5. Filter words

According to Chinese stop list, we should eliminate the stop list and low-frequency words. Stop list consists mainly of conjunction, modal particle, adverb, and high-frequency meaningless words. We retain the domestic words with frequency higher than 11 and foreign words with frequency higher than 31 , which are showed in Table 3. 


\subsubsection{LDA topic model}

As a good method of mass text mining, LDA topic model can reveal the topic of large scale documents and corpus, and dig advanced technology topics of patent documents. This paper tries to analyse the patent data of 20 companies from different angles via LDA, to gather more scientific and targeted information.

Table 3 - High-frequency words (top 10)

\begin{tabular}{|l|l|l|l|}
\hline \multicolumn{2}{|l|}{ foreign } & \multicolumn{2}{l|}{ domestic } \\
\hline subject headings & frequency & subject headings & frequency \\
\hline device & 7510 & module & 1579 \\
\hline connection & 3533 & device & 1376 \\
\hline settings & 3137 & circuit & 1351 \\
\hline component & 2728 & connection & 935 \\
\hline terminal & 2499 & signal & 853 \\
\hline switch & 2243 & control & 821 \\
\hline system & 1799 & terminal & 797 \\
\hline unit & 1668 & monitor & 730 \\
\hline current & 1443 & electric source & 597 \\
\hline open circuit & 1401 & switch & 595 \\
\hline
\end{tabular}

\subsubsection{Subject clustering}

The paper classifies the topics of patents data via LDA model, and defines the number of subjects artificially. We can see the distribution of feature term of domestic patents in Table 4. The above 5 subjects derived from LDA are made up of the high-frequency feature words which can represent research topics in patent field. Therefore, every subject can viewed as a hotspot of patent research. It is showed that the subjects of domestic patents are concentrated in apparatus, electricity, monitoring device, hardware and system.

It is showed that the subjects of foreign patents are concentrated in system, circuit device, circuit fault's solution, components, and settings in Table 5.

\subsection{Patent network hotspot analysis}

Co-word analysis originated from the middle and late 1970's, it mainly counts the frequency that two words from one group appearing in a document. The "co-occurrence" frequency can reflect the correlation degree of these words, and the certain subject's topical structure can be excavated via clustering analysis $\operatorname{method}^{7}$.We introduced it into hot-spots analysis, to statistics the co-occurrence frequency of two keywords in each patent for technology network chart drawing.

We pre-processed the text via BibExcel to generate co-occurrence matrix with the top 100 high-frequency words, then imported the matrix into UCINET, and mapped the knowledge network by Netdraw. You can refer to Fig. 3 and Fig. 4 to obtain the co-occurrence network of high-frequency words of domestic patent and foreign patent separately. 
Table 4 -The distribution of feature term of domestic patents (top 10 words)

\begin{tabular}{|l|l|l|l|l|l|l|l|l|l|}
\hline \multicolumn{2}{|c|}{ First class } & \multicolumn{2}{|c|}{ Second class } & \multicolumn{2}{c|}{ Third class } & \multicolumn{2}{c|}{ Fourth class } & \multicolumn{2}{c|}{ Fifth class } \\
\hline terminal & 0.17 & circuit & 0.22 & device & 0.18 & module & 0.30 & switch & 0.11 \\
\hline $\begin{array}{l}\text { connect- } \\
\text { ion }\end{array}$ & 0.16 & control & 0.13 & monitor & 0.13 & electric source & 0.09 & install & 0.08 \\
\hline plate & 0.10 & signal & 0.12 & data & 0.10 & instrument & 0.05 & settings & 0.05 \\
\hline light & 0.04 & unit & 0.09 & system & 0.08 & $\begin{array}{l}\text { electrical } \\
\text { energy }\end{array}$ & 0.04 & operation & 0.04 \\
\hline wiring & 0.04 & current & 0.07 & communication & 0.05 & measurement & 0.04 & component & 0.04 \\
\hline $\begin{array}{l}\text { main } \\
\text { body }\end{array}$ & 0.02 & voltage & 0.04 & electric & 0.04 & connection & 0.04 & circuit & 0.04 \\
\hline $\begin{array}{l}\text { resist- } \\
\text { ance }\end{array}$ & 0.02 & relay & 0.03 & alarm & 0.03 & communication & 0.04 & open circuit & 0.03 \\
\hline detection & 0.01 & $\begin{array}{l}\text { mutual } \\
\text { inductor }\end{array}$ & 0.03 & control & 0.03 & chip & 0.03 & $\begin{array}{l}\text { change-over } \\
\text { switch }\end{array}$ & 0.03 \\
\hline heat & 0.01 & SCM & 0.03 & sensor & 0.03 & electric power & 0.03 & shell & 0.03 \\
\hline $\begin{array}{l}\text { ill- } \\
\text { uminant }\end{array}$ & 0.01 & driver & 0.02 & parameter & 0.02 & processor & 0.03 & pedestal & 0.03 \\
\hline
\end{tabular}

Table 5 - The distribution of feature term of foreign patents (top 10 words)

\begin{tabular}{|l|l|l|l|l|l|l|l|l|l|}
\hline \multicolumn{2}{|c|}{ First class } & \multicolumn{2}{c|}{ Second class } & \multicolumn{2}{c|}{ Third class } & \multicolumn{2}{c|}{ Fourth class } & \multicolumn{2}{c|}{ Fifth class } \\
\hline system & 0.12 & unit & 0.10 & connection & 0.23 & component & 0.18 & device & 0.49 \\
\hline data & 0.07 & current & 0.09 & $\begin{array}{l}\text { open } \\
\text { circuit }\end{array}$ & 0.09 & terminal & 0.15 & settings & 0.11 \\
\hline input & 0.06 & voltage & 0.07 & shell & 0.08 & switch & 0.13 & module & 0.08 \\
\hline output & 0.05 & signal & 0.07 & insulation & 0.06 & axis & 0.04 & electric & 0.05 \\
\hline electric power & 0.05 & power & 0.05 & driver & 0.05 & settings & 0.04 & network & 0.03 \\
\hline settings & 0.05 & circuit & 0.05 & pole & 0.04 & tripping & 0.03 & electron & 0.03 \\
\hline electric source & 0.03 & detection & 0.04 & lock & 0.03 & transformer & 0.03 & close & 0.02 \\
\hline communication & 0.03 & breakdown & 0.04 & spring & 0.02 & conduction & 0.03 & relay & 0.01 \\
\hline control & 0.03 & converter & 0.03 & cable & 0.02 & winding & 0.03 & trip & 0.01 \\
\hline cooling & 0.03 & sensor & 0.02 & machine & 0.02 & metal & 0.03 & wireless & 0.01 \\
\hline
\end{tabular}

We can see "signal" in the centre of the network is the most important node, surrounding by module, current, system, circuit, monitor, power source and control.

"Device" surrounding by system, component, unit, terminal, current and switch indicates the research focus of foreign patents is hardware device.

\section{Conclusion}

This paper analyzed the technology status of energy-saving electricity enterprise via patents data, to estimate the production and management state after patents put into use, by combining sales of technical products. This study reached the following conclusions and suggestions: 
1. Total patent applications of electric industry keep increasing, while the growth rate is slowing down.

2. Invention has an under allocation in total patents, and patent quality has to be improved.

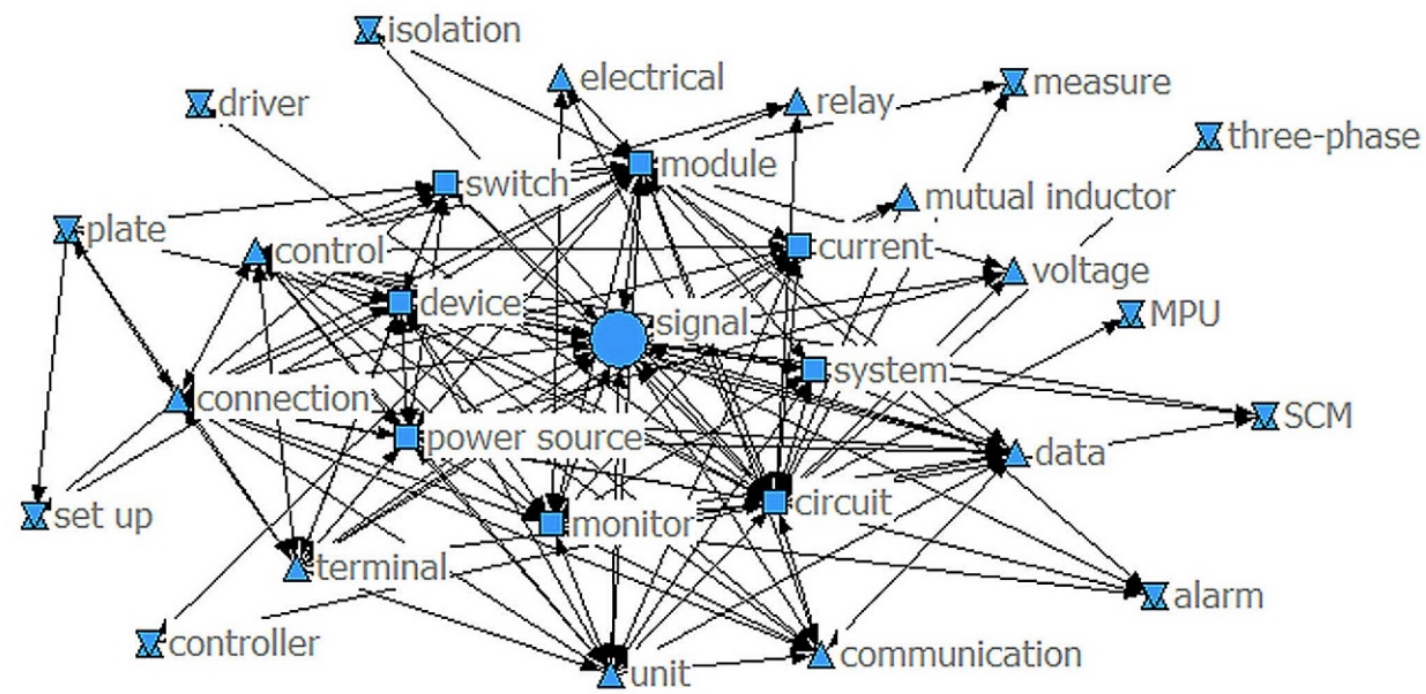

Fig.3 - Co-occurrence network of high-frequency words of domestic patent

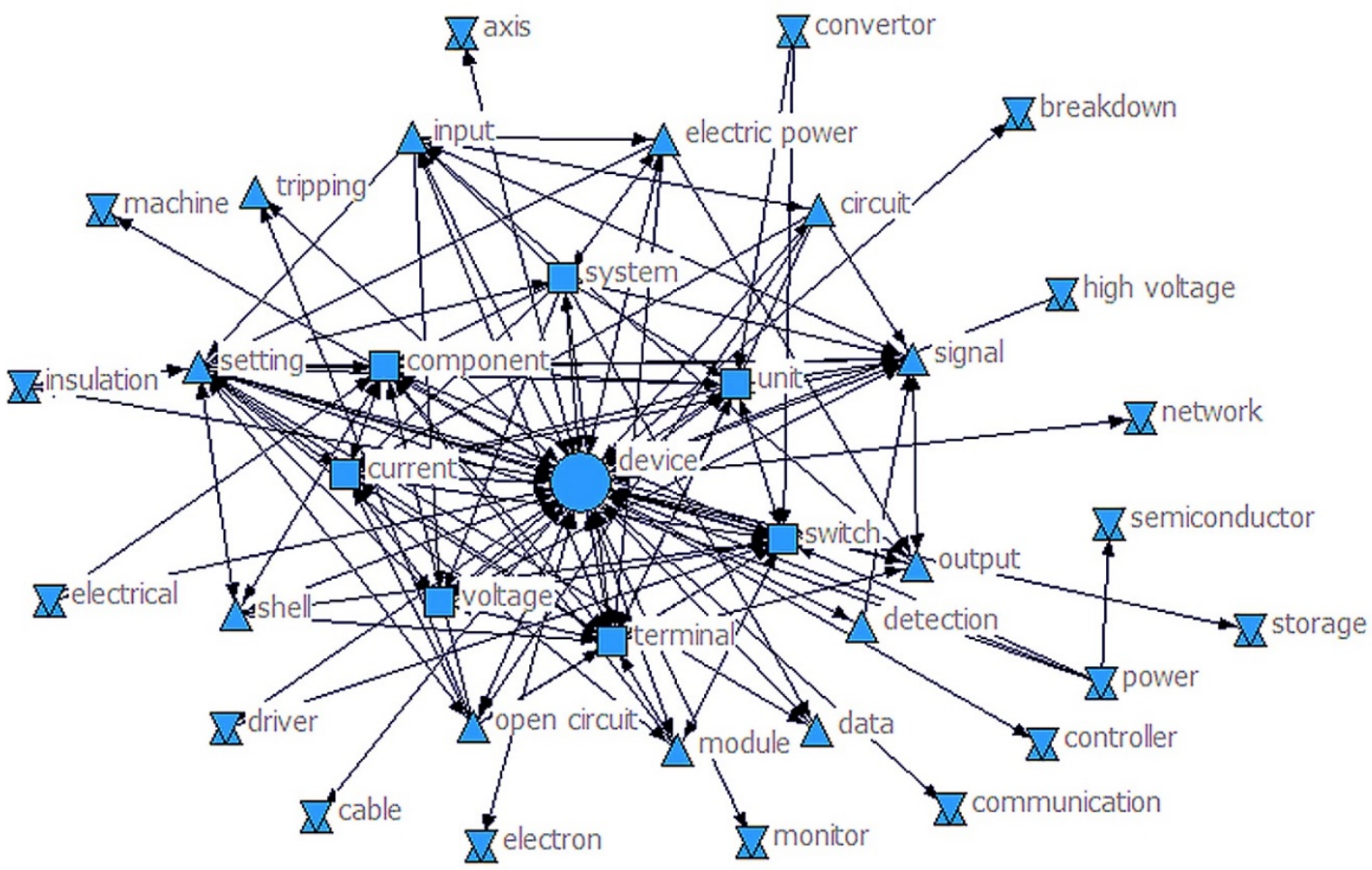

Fig. 4 -Co-occurrence network of high-frequency words of foreign patent

3. The industry technologies are similar for the same distribution of IPC. These enterprises have not formed technical advantages of their respective products. 
4. The patented technology is sophisticated enough due to the most patents are concentrated on $\mathrm{H}$-section and G-section which have few theory content. It is indicated that the applied patents are rather practical for commercial use.

5. There is an unbalance distribution of technology, and it keeps some pace with patent technology at home and abroad, which poses great threat to domestic enterprises.

6. The research focus of foreign patents is hardware device while focuses of domestic patents are monitoring device and fault processing, such as "signal".

With various preferential policies of energy saving and emission reduction, domestic enterprises who have a high cost performance in low-end market should seize the opportunity, to invest in technology, improve the quality of products, reduce costs and try to shift upmarket.

\section{Acknowledgements}

The work describe in this paper was fully supported by a grant from the Soft Science Research Project of Guangdong Province(Grant No.2014A030304013), and a grant from Teaching Reform Project (integrated class) of Guangdong Province (Grant No. GDJG201412 63).

\section{References}

1. B.Wang, S.B.Liu, K. Ding and Z.Y. Liu, , Method of patent content analysis based on LDA, Science Research Management. 03(2015) 111-117.

2. J.T. Gong, and J.T. Wei, Co-authorship network of patent based on social network analysis_ A case study of wind power technology patent in China. Journal of Intelligence, 32(11) (2013)37-42.

3. H.X. Zhong, Competition situation analysis of LED industry patent in Zhuhai, China. Journal of Intelligence. 33(6) (2014) 59-65.

4. H.Y. Lee, Y. Lee, and Q.Z. Peng, Enterprise positioning technology research based on patent analysis_ a case study of infrared detection technology, Information studies: Theory \&Application. 38(7) (2015)86-91.

5. L.Y.Huang, J. Wang and F.Tang, Application research of patent information analysis in science and technology development strategy formulation. Journal of Intelligence. 11(2011) 33-36.

6. J.F. Guo, constructing classification system for subject classification of Chinese shorttext based on LDA. Harbin Institute of Technology. (2014)

7. L.Cao, J. Yang, and Y. Xia, Co-word clustering analysis of national competitive intelligence research paper, Information Science. 06(2010) 923-928. 